\title{
Genetic Profile and Serosurvey for Virus Infections of Japanese Wild Boars in Shikoku Island
}

\author{
Naotaka ISHIGURO ${ }^{1)}$ and Masakazu NISHIMURA ${ }^{2)}$ \\ ${ }^{1)}$ Laboratory of Food and Environmental Hygiene, Faculty of Applied Biological Sciences, Gifu University, Gifu, 501-1193 and \\ ${ }^{2)}$ Laboratory of Veterinary Pharmacology, Obihiro University of Agriculture and Veterinary Medicine, Obihiro, 080-8555, Japan
}

(Received 24 September 2004/Accepted 21 February 2005) ABSTRACT. To estimate the genetic background of Japanese wild boars inhibiting the 4 prefectures of Shikoku Island (Kagawa, Tokushima,
Kouchi and Ehime), we examined haplotypes of mitochondrial DNA (mtDNA) and genotypes of the nuclear glucosephosphate
isomerase-processed pseudogene $(G P I P)$ in 189 wild boars. Of the 8 different mtDNA haplotypes (J5, J10, J12, J13, J15, J19, J20 and
E33) detected in Shikoku Island, the first to be identified were J19 and J20 (of Japanese wild boar lineage) and E33 (of European domes-
tic pig lineage). The presence of haplotype E33 indicates local crossbreeding between wild boar and escaped domestic pigs and/or cross-
bred Inobuta. Four kinds of the GPIP genotypes were detected from 189 wild baors in Shikoku Island, but no European GPIP alleles
were found. In 113 wild boars, no antibodies against Classical Swine Fever or Aujeszky's disease were detected, suggesting that they
had not been exposed to those pathogens.

KEY WORDS: allele, Aujeszky’s disease, haplotype, mitochondorial DNA, wild boar.

J. Vet. Med. Sci. 67(6): 563-568, 2005

The wild boar (Sus scrofa) is an ancestral species of domestic pigs, and is widely distributed throughout Asia, Europe and North Africa. Worldwide, wild boars are classified into at least 16 species [5]. Two subspecies of wild boar inhabit Japan: the Japanese wild boar (S. s. leucomystax), on 3 of the 4 Japanese main islands (Honshu, Kyushu and Shikoku); and the Ryukyu wild boar (S. s. riukiuanus), on the Ryukyu Islands [13]. In recent decades, the numbers of Japanese wild boars has rapidly increased in several prefectures in Honshu, Kyushu and Shikoku [2]. The increasing numbers of Japanese wild boar around mountainous villages have caused serious problems including damage to farms and crops. In the past 3 decades in many prefectures in Japan, there has been an increase in the number of farms that breed wild boars and farms that cross-breed domestic pigs and wild boars to produce the crossbred Inobuta [8]. Wild boars and Inobuta, crossbred of domestic pig and wild boar, occasionally accidentally escape from breeding farms [8]. Escapes from these farms may influence the genetic structure, epidemiological status and population size of wild boars. The frequency of such escapes has not been accurately determined.

Recently, Ishiguro et al. [6] developed a genetic method that uses haplotypes of mitochondrial DNA (mtDNA) and genotypes of the nuclear glucosephosphate isomerase-processed pseudogene (GPIP) [4] to distinguish crossbred Inobuta from Japanese wild boars. There is the potential for transmission of infectious diseases between domestic pigs and feral wild boars. Specific antibodies against Aujeszky's disease have been detected in feral wild boars in an area of Honshu Island [1].

In the present study, we examined the genetic background and antibody profile of Japanese wild boars on Shikoku Island. Numbers of wild boars have increased rapidly in 4 of the prefectures of Shikoku (Kagawa, Tokushima, Kouchi and Ehime). Here, we report the results of genetic classification of 189 wild boars killed by hunters in 4 prefectures of Shikoku Island, using mtDNA and GPIP markers and titers of antibodies against Classical Swine Fever (CSF) and Aujeszky's disease (AD).

\section{MATERIALS AND METHODS}

Animal samples: A total of 189 muscle samples of Japanese wild boars (98 males, 74 females and 17 unknown) were collected from animals on Shikoku Island: 50 animals in Kagawa Prefecture, 50 animals in Tokushima Prefecture, 41 animals in Kouchi Prefecture, and 48 animals in Ehime Prefecture (Table 1). The samples were obtained from Japanese wild boars killed by shooting in these 4 prefectures from November 2003 to February 2004. Blood samples were collected from 33 animals in Kagawa Prefecture, 30 animals in Tokushima Prefecture, 8 animals in Kouchi Prefecture, and 42 animals in Ehime Prefecture.

DNA extraction and mtDNA analysis: Total DNA was extracted from the muscle samples using the DNeasy Tissue Kit (Qiagen Science, MD). This total DNA was used for polymerase chain reaction (PCR) amplification of mtDNA and the GPIP gene. The mtDNA D-loop region (574 bp) was amplified with 2 primers (mt112 and mit106), and purified with a QIAquick PCR Purification Kit (Qiagen). The DNA sequence of the mtDNA D-loop region was determined by the direct sequence method using 2 primers (mit11 and mit12), as described previously [6,9]. Multiple sequence alignment was performed using GENETYX-MAC software (Software Development Co., Tokyo, Japan). Haplotypes of the 574-bp mtDNA were used in neighbor-joining analysis [12], which was performed using the PHYLIP program package, version 3.572 [3]. Sixty-three previously reported haplotypes (accession nos: D42170-D42174, 
Table 1. Genetic profiles and antibody titer of Japanese wild boars isolated from four prefectures in Shikoku Island

\begin{tabular}{|c|c|c|c|c|c|c|c|c|c|c|}
\hline \multirow{3}{*}{$\begin{array}{l}\text { Prefecture } \\
\text { (No. of } \\
\text { sampling sites) }\end{array}$} & \multirow{3}{*}{$\begin{array}{l}\text { No. of } \\
\text { samples }\end{array}$} & \multicolumn{6}{|c|}{ Genetic profiles } & \multicolumn{3}{|c|}{ Antibody titer } \\
\hline & & \multirow{2}{*}{$\begin{array}{r}\text { mtDNA } \\
\text { haplotype }\end{array}$} & \multirow{2}{*}{$\begin{array}{l}\text { No. of } \\
\text { samples }\end{array}$} & \multicolumn{2}{|c|}{ GPIP genotype } & \multirow[b]{2}{*}{$G P I P * 3 a / G P I P * 3 a$} & \multirow[b]{2}{*}{$G P I P^{*} 1 / G P I P^{*} 3$} & \multirow{2}{*}{$\begin{array}{l}\text { No. of } \\
\text { samples tested }\end{array}$} & \multicolumn{2}{|c|}{ Titer to } \\
\hline & & & & $G P I P^{*} 1 / G P I P^{*} 1$ & $G P I P^{*} 3 / G P I P^{*} 3$ & & & & $\mathrm{CSF}^{\mathrm{a})}$ & $\mathrm{AD}^{\mathrm{b})}$ \\
\hline \multirow[t]{3}{*}{ Kagawa (18) } & 50 & J5 & 6 & 1 & 1 & 4 & & 33 & _c) & $<4^{\text {d) }}$ \\
\hline & & J12 & 6 & 0 & 1 & 5 & & & & \\
\hline & & J19 & 38 & 7 & 6 & 24 & 1 & & & \\
\hline \multirow[t]{6}{*}{ Tokushima (38 } & 8) 50 & J5 & 3 & 0 & 0 & 3 & & 30 & - & $<4$ \\
\hline & & $\mathrm{J} 10$ & 3 & 0 & 0 & 3 & & & & \\
\hline & & J12 & 19 & 4 & 0 & 15 & & & & \\
\hline & & $\mathrm{J} 13$ & 3 & 1 & 0 & 2 & & & & \\
\hline & & $\mathrm{J} 15$ & 13 & 2 & 0 & 11 & & & & \\
\hline & & J19 & 9 & 1 & 0 & 8 & & & & \\
\hline \multirow[t]{5}{*}{ Kouchi (12) } & 41 & $\mathrm{~J} 10$ & 4 & 0 & 0 & 4 & & 8 & - & $<4$ \\
\hline & & $\mathrm{J} 12$ & 25 & 11 & 0 & 14 & & & & \\
\hline & & $\mathrm{J} 13$ & 3 & 2 & 0 & 1 & & & & \\
\hline & & $\mathrm{J} 15$ & 6 & 4 & 0 & 2 & & & & \\
\hline & & J19 & 3 & 3 & 0 & 0 & & & & \\
\hline \multirow[t]{7}{*}{ Ehime (44) } & 48 & J5 & 3 & 2 & 0 & 1 & & 42 & - & $<4$ \\
\hline & & $\mathrm{J} 10$ & 1 & 1 & 0 & 0 & & & & \\
\hline & & $\mathrm{J} 12$ & 27 & 18 & 0 & 9 & & & & \\
\hline & & $\mathrm{J} 15$ & 8 & 5 & 0 & 3 & & & & \\
\hline & & J19 & 4 & 2 & 0 & 2 & & & & \\
\hline & & $\mathrm{J} 20$ & 2 & 1 & 0 & 1 & & & & \\
\hline & & E33 & 3 & 1 & 0 & 2 & & & & \\
\hline Total & 189 & & 189 & 66 & 8 & 114 & 1 & 113 & & \\
\hline
\end{tabular}

a) CSF, Classical Swine Fever.

b) $\mathrm{AD}$, Aujeszky's disease.

c) -, Optimal density is lower than 0.09 in ELISA Kit.

d) $<4$, Serum dilutions are lower than 4 hold in AD Latex Kit.

D42178-D42185, AB015087-AB015086, AB041465$\mathrm{AB} 041473, \mathrm{AB} 041474-\mathrm{AB} 041476, \mathrm{AB} 041479-\mathrm{AB} 041485$, AB041487-AB041493, AB041495-AB041499, AB053623$\mathrm{AB} 053627, \mathrm{D} 42176, \mathrm{AB} 071706, \mathrm{AB} 071707$ and $\mathrm{AB} 055222)[6,10,11,14,15]$ were used as reference sequences in NJ analysis.

GPIP haplotype analysis: The 507-bp GPIP sequence was amplified with the primers GPIP1 and GPIP6, and purified with the QIAquick PCR Purification Kit. The DNA sequence of the 507-bp GPIP sequence was determined by the direct sequence method, as described previously [6]. The GPIP alleles $\left(G P I P^{*} 1, G P I P^{*} 3, G P I P^{*} 3 a, G P I P^{*} 4\right.$ and $G P I P^{*} 4 a$ ) were determined by comparison with previously reported GPIP sequences [6, 9].

Measuring titers of antibodies against CSF and AD: Titers of antibodies against CSF and AD in 113 serum samples from Japanese wild boars were determined using the Hog Cholera ELISA Kit (Chitsuso, Inc, Yokohama, Japan) and AD Antigen Latex "Zennou” (Vira/Antigens Inc. Memphis, ME), respectively, in accordance with the manufacturers' instructions. The sera were heat-inactivated at $56^{\circ} \mathrm{C}$ for $30 \mathrm{~min}$, and were used at the dilution appropriate for the respective kit.

\section{RESULTS}

Distribution of mtDNA haplotypes of Japanese wild boars: Table 2 shows the nucleotide variation of 3 new mtDNA haplotypes (J19, J20 and E33) aligned with those of previously reported $\mathrm{mtDNA}$ haplotypes [6]. A total of 8 different mtDNA haplotypes (J5, J10, J12, J13, J15, J19, J20 and E33) were detected in wild boars on Shikoku Island, and the haplotypes J12 (41\%) and J19 (29\%) were the most prevalent of these (Table 2). The haplotype E33, detected in Ehime Prefecture, had a pattern of nucleotide variation that differed considerably from those of the 20 haplotypes ( $\mathrm{J} 1$ to J20) that were shown by NJ analysis to belong to a European lineage (Fig. 1).

The NJ relationships among the 21 haplotypes ( $\mathrm{J} 1$ to $\mathrm{J} 20$ and E33) and 45 haplotypes from domestic pigs and wild boars worldwide showed 2 major clusters: Asian type (63\% bootstrap value) and European type (63\% bootstrap value) (Fig. 1). Five mtDNA haplotypes of Japanese wild boar (J10, J12, J13, J15 and J20) were classified into group 2, and 2 haplotypes of Japanese wild boar (J5 and J19) were classified into group 1. The mtDNA haplotype E33 was classified as belonging to a European domestic pig lineage. The wild boars with E33 haplotype appear to be genetically related to 
Table 2. Nucleotide variations of Japanese wild boars

\begin{tabular}{|c|c|c|}
\hline & & Nucleotide positions $^{\text {b) }}$ \\
\hline Haplotype $^{\text {a) }}$ & $\begin{array}{c}\text { No.of } \\
\text { samples }\end{array}$ & $\begin{array}{l}11111111112222233334455556666667 \\
33345588881668900894504673456890 \\
16864923565180537914323168183433\end{array}$ \\
\hline $\mathrm{J} 1$ & & A- - TTGCTCTTCCCGATATATGATGGCTCAAA \\
\hline $\mathrm{J} 2$ & & $\ldots \ldots \ldots \ldots \ldots \ldots$ \\
\hline $\mathrm{J} 3$ & & $\ldots$ A $\ldots$ Т. . С . \\
\hline $\mathrm{J} 4$ & & $\ldots \ldots$ A..... . . A. \\
\hline $\mathrm{J} 5$ & 12 & $\ldots \ldots \ldots \ldots \ldots \ldots \ldots \ldots$ C . C \\
\hline $\mathrm{J} 6$ & & $\ldots \ldots \ldots \mathrm{C} \ldots \mathrm{T} \ldots \ldots \ldots \mathrm{C} \ldots \mathrm{C}$. \\
\hline $\mathrm{J} 7$ & & $\ldots \ldots \ldots \ldots$ T. . . . . . . CTC . \\
\hline $\mathrm{J} 8$ & & $\ldots \ldots \ldots \ldots$. . . . . . . CT . \\
\hline J9 & & $\ldots \ldots \ldots \ldots \ldots \ldots \ldots \ldots \ldots$ \\
\hline $\mathrm{J} 10$ & 8 & $\ldots \ldots \ldots \ldots \ldots \ldots \ldots$. \\
\hline $\mathrm{J} 11$ & & $\ldots \ldots \ldots \ldots \ldots \ldots$ G...A.C. \\
\hline $\mathrm{J} 12$ & 77 & $\ldots \ldots \ldots \ldots \ldots$ G. . . . C \\
\hline $\mathrm{J} 13$ & 6 & $\ldots \ldots \ldots \ldots$ G $\ldots$ CG . . . C \\
\hline $\mathrm{J} 14$ & & $\ldots \ldots \ldots \ldots$ G.G. . C . C \\
\hline $\mathrm{J} 15$ & 27 & $\ldots \ldots \ldots \ldots \ldots \ldots \ldots \ldots$ C. . \\
\hline $\mathrm{J} 16$ & & $\ldots \ldots \ldots \mathrm{G}$ \\
\hline $\mathrm{J} 17$ & & $\ldots \ldots \ldots$. . . . . . . . \\
\hline $\mathrm{J} 18$ & & $\ldots \ldots \ldots$. AGC . . . . . C \\
\hline $\mathrm{J} 19$ & 54 & $\ldots \ldots \mathrm{CT} . \mathrm{C} \ldots \mathrm{T} \ldots \ldots \ldots$ \\
\hline $\mathrm{J} 20$ & 2 & $\ldots \ldots \mathrm{T} \ldots \ldots \mathrm{G}$ \\
\hline E33 & 3 & GC.CCAT ..... TA.C.C.CA. A . C . . G \\
\hline Total & 189 & \\
\hline
\end{tabular}

a) Haplotypes $\mathrm{J} 1$ to J18 are defined in the previous paper [6]. New three haplotypes J19, J20 and E33 are detected in the present study.

b) Nucleotide position 1 corresponds to the first position of the complete DNA sequences of mtDNA control region described by Okumura et al. [10]. Dots indicate the nucleotide identity with Japanese wild boar haplotype J1.

crossbred Inobuta with a European mtDNA lineage.

The distribution of mtDNA haplotypes in each prefecture is summarized in Table 1. In Kagawa Prefecture, $3 \mathrm{mtDNA}$ haplotypes (J5, J12 and J19) were detected, and the haplotype J19 (76\%) was the predominant haplotype. Among the 6 mtDNA haplotypes detected in Tokushima Prefecture, the haplotypes J12 and J15 were predominant. Among the 5 mtDNA haplotypes (J10, J12, J13, J15 and J19) detected in Kouchi Prefecture, the haplotype J12 was predominant. In Ehime Prefecture, 6 haplotypes belonging to Japanese wild boar lineage and 1 haplotype (E33) belonging to European domestic pig lineage were detected (Table 1). The geographical distribution of mtDNA haplotypes detected on Shikoku Island is plotted in Fig. 2. The map shows that the haplotype J19 is concentrated in the border region between Kagawa and Tokushima Prefectures. Haplotype J19 has not been detected in wild boars from Honshu or Kyushu Islands $[6,15]$, and thus appears to be indigenous to Shikoku Island. The mtDNA haplotype J13 was only found in Tokushima and Kouchi Prefectures. The nucleotide sequences of the new haplotypes J19, J20 and E33 have been submitted to the nucleotide databases of GenBank, EMBL and DDBJ with the following accession numbers: AB188576 (J19), AB188577 (J20) and AB188578 (E33).

In allele analysis of nucleotide substitutions at 8 variable sites in the 507-bp fragment of GPIP [6] of 189 wild boars, performed to estimate the genetic influence of domestic pigs on feral wild boars, 3 alleles $\left(G P I P^{*} 1, G P I P^{*} 3\right.$ and $G P I P * 3 a)$ were identified. No European alleles $(G P I P * 4$ and $G P I P^{*} 4 a$ ) were found in those samples. Table 1 shows the GPIP genotypes of wild boars in each prefecture. All genotypes that were detected $\left(G P I P^{*} 1 / G P I P^{*} 1, G P I P^{*} 3 /\right.$ $G P I P^{*} 3, G P I P^{*} 3 a / G P I P^{*} 3 a$ and $G P I P^{*} 1 / G P I P * 3 a$ ) were of Japanese wild boars. The genotypes GPIP*3/GPIP*3 and $G P I P * 1 / G P I P * 3 a$ were only found in Kagawa Prefecture (Table 1).

Serosurvey: The optimal density of titers of antibodies against CSF was lower than 0.09 at 50 -fold dilution. No anti-AD antibodies were detected in serum at dilutions greater than 4-fold (Table 1).

\section{DISCUSSION}

The present results summarize the genetic background of Japanese wild boars on Shikoku Island, which has not been as well characterized as those of Japanese wild boars on Kyushu and Honshu Islands [15]. We detected 2 new mtDNA haplotypes (J19 and J20) in wild boars on Shikoku Island. The haplotypes J19 and J20 were classified into group 1 and group 2, respectively (Fig. 1). Watanobe et al. [15] reported that the ancestral population of Japanese wild boars in group 1 (clades 2-1 and 2-2 in the previous paper 


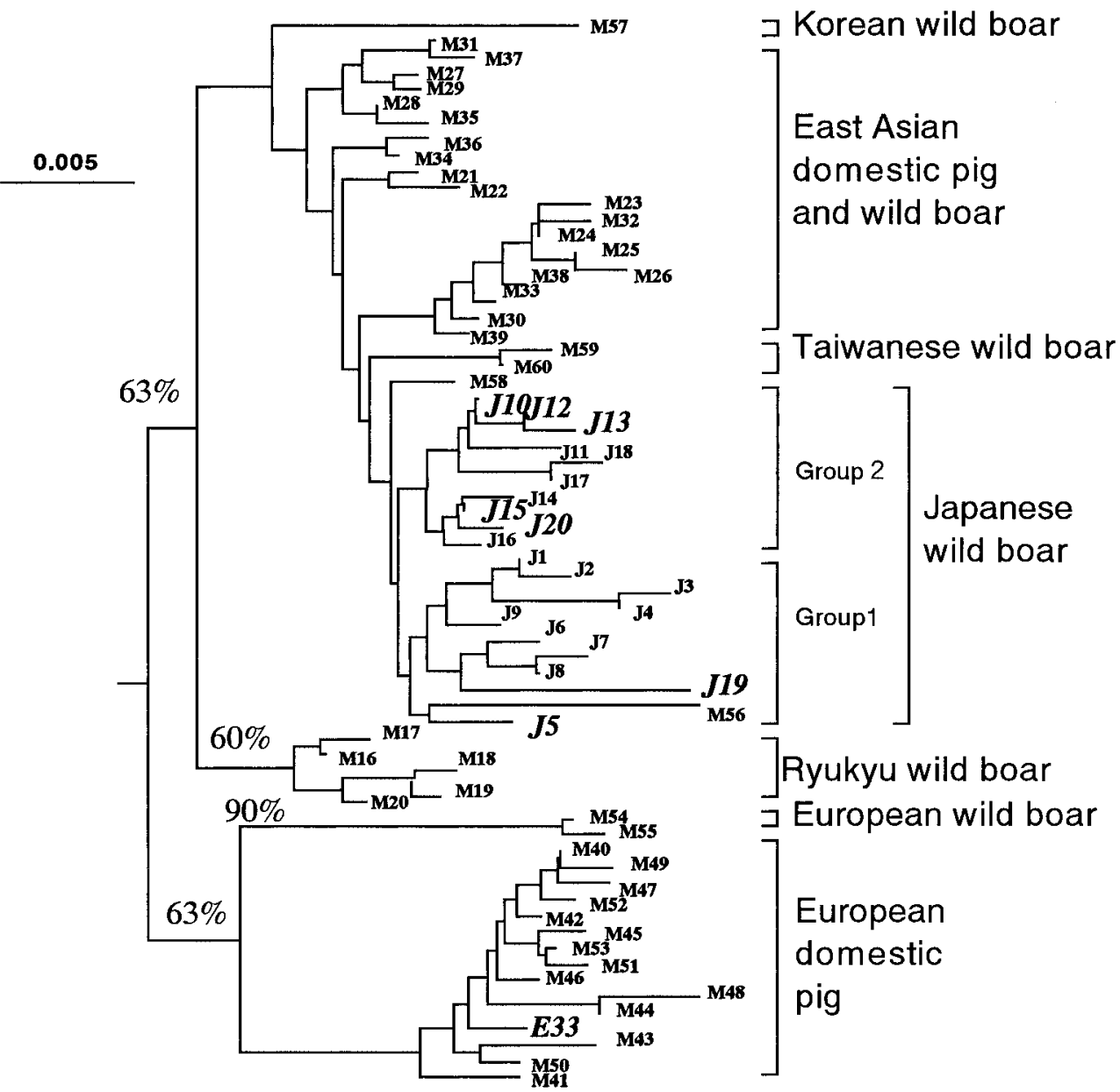

Fig. 1. Neighbor-joining phylogenetic tree constructed by the NJ method using the 574-bp mtDNA control region of 20 Japanese wild boars (J1 to J20) and 46 other Sus scrofa haplotypes: Korean wild boar (M56 and M57); East Again domestic pig and wild boars (M21 to M39); Taiwanese wild boar (M58 to M60); Ryukyu wild boar (M16 to M20); European wild boar (M54 and M55); European domestic pig (M40 to M53 and E33). Large italic numbers are haplotypes detected in the present study. Bootstrap resampling was performed 1000 times, and the bootstrap probabilities greater than $50 \%$ are shown on the corresponding branches.

[15]) and group 2 (clade 2-3) independently diverged from Northeast Asian wild boars at 170000 to 367000 and 12 000 to 21000 years ago, respectively. The ancestral population of Japanese wild boars probably migrated from the Korean Peninsula to Kyushu Island across land bridges that repeatedly formed between the Korean Peninsula and Kyushu Island, and subsequently spread to Honshu and Shikoku Islands. The mtDNA haplotype J19 shows a characteristic genetic distance in nucleotide variations, compared with Japanese wild boars in group 1 (Fig. 1). The mtDNA haplotype J19 was not observed in any wild boars from Kyushu or Honshu Islands, suggesting that wild boars with haplotype J19 only survived in a limited area on Shikoku Island after Shikoku Island became geographically isolated from Kyushu and Honshu Islands. The local distribution of wild boars with haplotype J19 in the boundary region (Shikoku Mountains) between Kagawa and Tokushima Prefectures supports the hypothesis that J19 wild boars are descendants of native wild boars that were isolated in the Middle to Late Pleistocene [7].

We examined the genetic influence of domestic pigs on Japanese wild boars in Shikoku Island, using mtDNA haplotypes (maternal inheritance) and GPIP genotypes (biparental inheritance). Three Japanese wild boars with the European mtDNA haplotype E33 were identified in Ehime Prefecture, indicating that crossbred Inobuta exist in a limited area on Shikoku Island. The presence of crossbred Inobuta and introgression from domestic pigs to Japanese wild boars have been demonstrated by mtDNA haplotype analysis of Japanese wild boars in other prefectures [6]. On Shikoku Island, the number of wild boars has increased markedly in the last decade [2]. It is unclear whether this 


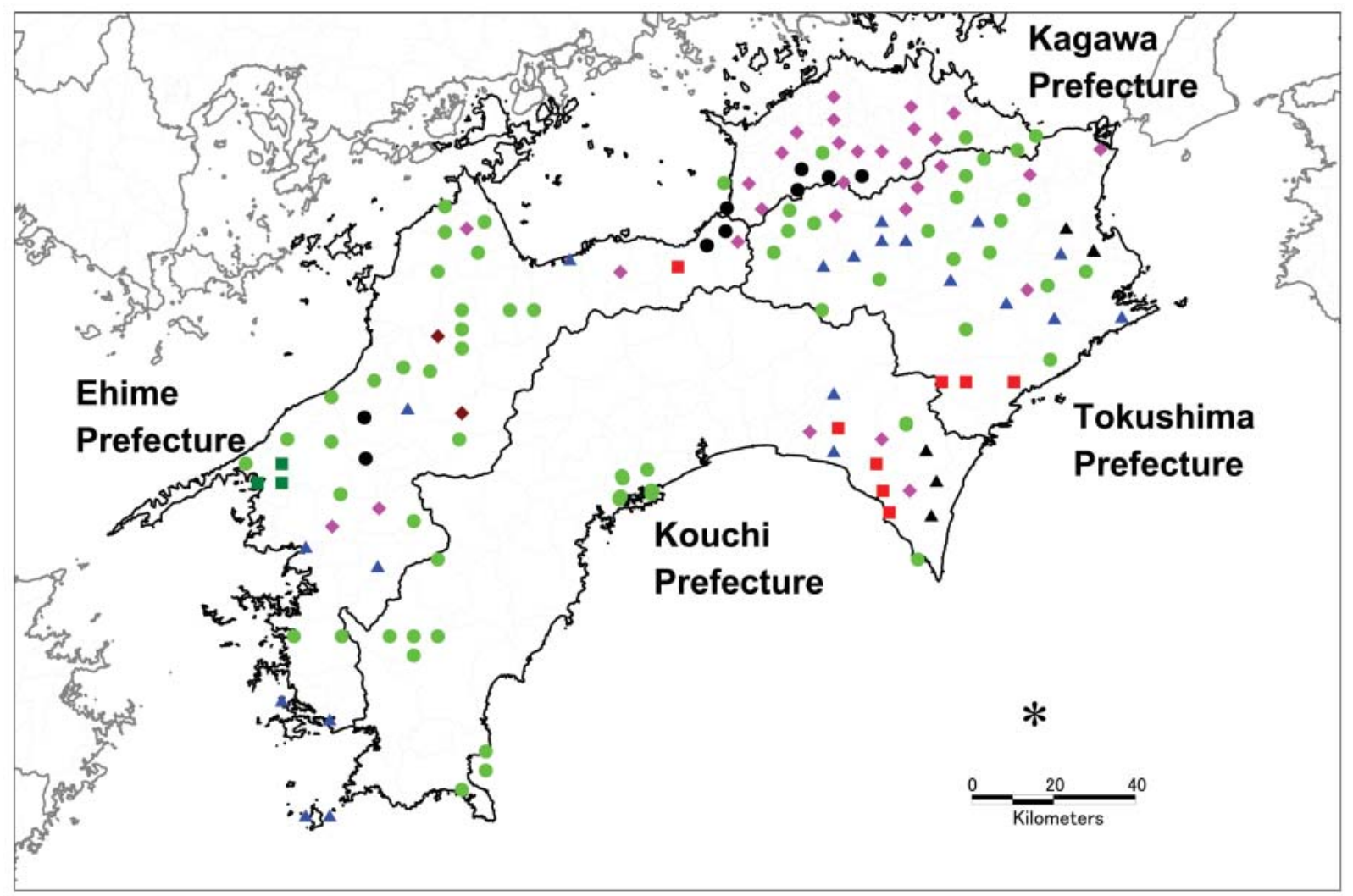

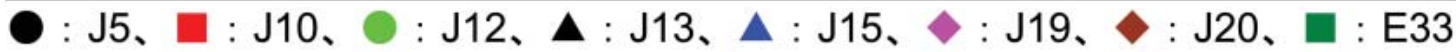

Fig. 2. Distribution of mtDNA haplotypes detected in Japanese wild boars on Shikoku Island. mtDNA haplotypes are indicated by the symbols.

increase in the number of wild boars has been caused by transmission of certain genetic properties from domestic pigs to wild boars. Kodera and Kanzaki [8] reported that there are farms that breed wild boars and crossbreeds in 30 $(63.8 \%)$ and $22(46.8 \%)$ prefectures in Japan, respectively. The crossbred Inobuta has generally been produced by crossing a male wild boar with a feral domestic pig on the breeding farm. The piglets produced by this crossbreeding have all the same haplotypes as their domestic pig mother. It is not clear whether wild boars with the E33 haplotype have escaped from breeding farms, and multiple crossbreeding between escaped domestic pigs and native wild boars may occur in the wild.

To distinguish the crossbred Inobuta from wild boar, nuclear GPIP genotyping is used together with mtDNA haplotyping, because the combination of mtDNA and GPIP analyses is suitable for detection of crossbred lineages in wild boar populations [6]. No wild boars with European GPIP alleles $\left(G P I P^{*} 4\right.$ and $\left.G P I P^{*} 4 a\right)$ were identified in the present study. Four kinds of GPIP genotype by combination of the alleles $G P I P^{*} 1, G P I P^{*} 3$ and $G P I P^{*} 3 a$ were detected from wild boars in Shikoku Island (Table 1). The GPIP genotypes were not unbalanced but were wildly geographically distributed on Shikoku Island (data not shown).
The escape or unsystematic artificial introduction of domestic pigs or crossbred Inobuta from breeding farms to the wild has led to other effects on wild boars in terms of infectious diseases. In a previous study, specific antibodies against $\mathrm{AD}$ were detected at high frequency in wild boars from Wakayama Prefecture [1]. It has been reported that hunting dogs used to hunt wild boars have died after they ate the carcasses of wild boars killed by AD infection in Nara Prefecture (Kouda et al., The 129th Annual Meeting of the Japanese Society of Veterinary Science, Tukuba, 2000). These results suggest that AD infection is present among wild boars in a limited area, in addition to domestic pigs. $\mathrm{AD}$ appears to have been transmitted from domestic pigs to wild boars after it was transmitted to domestic pigs in Japan. In the present serosurvey, no specific antibodies against AD were detected in wild boars from Shikoku Island, indicating that wild boars on Shikoku Island are still free from AD infection.

CSF is a very important contagious disease of the genus Sus. A national program to eradicate CSF has been conducted for several years, and CSF serosurveys have been conducted mainly with domestic pigs. No antibody titers were detected in 2914 wild boars tested from 1996 to 2000 in Japan (http://lin.lin.go.jp/maff/frame04.html). Introgres- 
sion from domestic pigs to Japanese wild boars has been frequent [6], and serosurveys for infectious diseases in wild boars are thus a useful method for estimating disease prevalence in the genus Sus worldwide.

ACKNOWLEDGMENTS. This study was supported in part by an annual investigation "Ecological Surveillance of Japanese Wild Boars in Shikoku Four Prefectures" conducted by Shikoku Four Prefectures, and by a Grant-in-Aid for Scientific Research (The 21st Century Center-of-Excellence Program; E-1) from the Ministry of Education, culture, Sports, Science and Technology of Japan.

\section{REFERENCES}

1. Animal Hygiene Weekly. 2002. No. 2733: 393.

2. Environmental Agency, Japan (1997-2002). ChoujyuuKankei-Toukei (in Japanese).

3. Felsenstein, J. 1995. PHYLIP version 3.572 Excecutables for Power Mac. Univ. Washington, Seattle.

4. Giuffra, E., Kijas, J.M.H., Amarger, V., Carlbory, O., Jeon, J.T. and Andersson, L. 2000. The origin of the domestic pigs: Independent domestication and subsequent introgression. Genetics 154: 1785-1791.

5. Herre, W. and Rohrs, M. 1977. Zoological considerations on the origins of farming and domestication. pp. 245-279. In: Origins of Agriculture (Reed, C.A. ed.), Mouton, The Hague.

6. Ishiguro, N., Naya, Y., Horiuchi, M. and Shinagawa, M. 2002. A genetic method to distinguish crossbred Inobuta from Japanese wild boars. Zool. Sci. 19: 1313-1319.

7. Kawamura, Y. 1982. Biogeographical aspects of the Quatermary mammals of Japan. Honyurui Kagaku 43-44: 99-130 (in Japanese).
8. Kodera, Y. and Kanzaki, N. 2001. Present status of wild boar and crossbred pig $\mathrm{x}$ wild boar farming and their feral populations in Japan. Wildlife Conserv. Jpn 6: 67-78 (in Japanese with English abstract).

9. Naya, Y., Horiuchi, M., Ishiguro, N. and Shinagawa, M. 2003. Bacteriological and genetic assessment of game meat from Japanese wild boars. J. Agric. Food Chem. 51: 345-349.

10. Okumura, N., Ishiguro, N., Nakano, M., Hirai, K., Matsui, A. and Sahara, M. 1996. Geographic population structure and sequence divergence in the mitochondrial DNA control region of the Japanese wild boar (Sus scrofa leucomystax), with reference to those of domestic pigs. Biochem. Genet. 34: 179-189.

11. Okumura, N., Kurosawa, Y., Kobayashi, E., Watanobe, T., Ishiguro, N., Yasue, H. and Mitsuhashi, T. 2001. Genetic relationship amongst the major non-coding regions of mitochondrial DNAs in wild boars and several breeds of domesticated pigs. Anim. Genet. 32: 139-147.

12. Saitou, N. and Nei, M. 1987. The neighbor-joining method: a new method for reconstructing phylogenetic trees. Mol. Biol. Evol. 4: 406-425.

13. Watanobe, T., Okumura, N., Ishiguro, N., Nakano, M., Matsui, A., Sahara, M. and Komatsu, M. 1999. Genetic relationship and distribution of the Japanese wild boar (Sus scrofa leucomystax) and Ryukyu wild boar (Sus scrofa riukiuanus) analyzed by mitochondrial DNA. Mol. Ecol. 8: 1509-1512.

14. Watanobe, T., Ishiguro, N., Okumura, N., Nakano, M., Matusi, A., Hongo, H. and Ushiro, H. 2001. Ancient mitochondrial DNA reveals the origin of Sus scrofa from Rebun Island, Japan. J. Mol. Evol. 52: 281-289.

15. Watanobe, T., Ishiguro, N. and Nakano, M. 2003. Phylogeography and population structure of the Japanese wild boar Sus scrofa leucomystax: Mitochondrial DNA variation. Zool. Sci. 20: $1477-1489$. 